\title{
Analyzing Fertility Trends and Future Prospect through Gompertz Model in Bihar State of India
}

\author{
Amit Kumar \\ Department of Migration \&Urban Studies, International Institute for Population Sciences, Mumbai, India
}

\begin{abstract}
Several Indian states have achieved or on the way of achieving the replacement level fertility, but the performance of Bihar are far from this. Accordingly, this paper attempts to assess the level and trends of fertility in across districts of fertility and its future prospect. Results shows that TFR is slow decline among districts but yet some districts have high TFR and substantial differences across the socio-economic groups. Contraceptive prevalence rate is marginal differs across the socio-economic groups in the state. Result of Gompertz Model indicates that rate of decline in TFR is decelerate after 1997, Low literacy, Low urbanization preceding poverty are may be other important factors, which may be the cause for decelerate. The projection of result indicates that at present projected TFR for the state is 3.66 (2010), which is far away from target of achieve to replacement of fertility till 2010 by national policy agenda. Moreover the pace of fertility decline seems very slow in coming years. For instance, in 2020 it will reach at the level 2.8 and by 2030 it will reduced only up to 2.2. After very long (2035) time, TFR of the state will achieve at replacement level. The Government's intervention should focus more first is the local level need based planning for family welfare programmes.
\end{abstract}

Key Words: Fertility, Gompertz model, Projection, Replacement level, Trend

\section{INTRODUCTION}

Fertility transition in India states started in as early as 1950s. India was the first country officially to start a family planning program funded by public finances. Many states showed early decline especially in the south where the population responded well to the program. The fertility transition in the south has reached the end now registering a significant decline during the last four decades. Factors like high female literacy, agrarian reforms, matrilineal customs, better health and educational facilities, government sponsored welfare measures, and political consciousness are believed to be responsible for the rapid and unusual demographic transition in the South.

However, except Punjab and West Bengal, the fertility transition in most of the states started in late 1960s. Bihar and Uttar Pradesh were the states where the fertility transition started even in late 1970s.

But the pace and levels of fertility transition in Bihar are relatively underexplored and have received very little attention compared to other north India states such as Madhya Pradesh and Uttar Pradesh. This paper attempts to take stock of the fertility trend in Bihar over the years. The rare opportunity to examine fertility trend and contraceptive use by three important large-scale demographic surveys carried out in the state, followed by District Level Household Survey (DLHS-1 \& 2) and National Family Health Survey (NFHS-1, 2 \& 3), apart from census and official statistics like Sample Registration System. A comparative analysis of data and findings from these major surveys will provide us sufficient information to understand the changes fertility patterns during the last five decades in the state.

\section{NEED OF THE STUDY}

A fertility analysis is one of the most-useful inputs to the developmental programmes such as education, reproductive and child health services, population stabilization and human development at both the national and sub-national levels. The National Population Policy launched in 2000 has a medium term objective to achieve the replacement level fertility by 2010 . It also envisages states to bring their policies, giving priority to local issues in coherence with the goals and objectives prescribed in the national policy. Henceforth, several states have brought out their policies to attain the replacement level fertility within a rational time frame and the prevailing socio-economic status of the people. According many of the state achieved the replacement level of the fertility, but the condition is worse in Bihar as it is a state with highest TFR. Moreover, the achievement of replacement level fertility is seen very difficult within concerned time frame, Moreover fertility also varies substantially across the districts of Bihar. However, to achieve such an objective one needs to understand the fertility variations within the state. Therefore, the district level fertility estimates and state level projection are not only appropriate, but also necessary to execute any policy or programme effectively. 


\section{DATA}

The present paper is base on the secondary data obtained from Sample Registration System (SRS), Registrar General of India, during 1981 to 2007. To analyze the trend analysis of total fertility rate at districts level, data taken from Registrar General of India (1997) '(District level Estimates of Fertility and Mortality for and their inter-relations with other variables), occasional paper No 1 of 1997 used. Census of India 2001 provides district level total numbers of woman, children ever born and total birth of last year; these data are used to compute the total fertility rate at districts level. The district level Schedule Castes \& Schedule Tribes, Hindu, Muslim, level of urbanization, literacy rate, female literacy rate, and woman work participation rate has taken from census of India 1981, 1991 \& 2001.

All three rounds of District Level Household Survey-1998-99, 2002-04, and 2007-08 are used to estimate the total fertility rate at district level as were as examine the differentials. The birth order first and second data collected in DLHS-1 \& 2 are used to estimate fertility rate. More specifically, these two data set (NFHS \& DLHS) are used to examine the differentials in contraceptive prevalence rate in the state. Data on Couple protection rate are obtained from Family welfare statistics 2006 (Ministry of Family Welfare and Health, Government of India) during 1980 to 2005.

\section{METHODOLOGY}

Arriaga's P/F Ratio method: To calculate the Total Fertility Rate Arriaga's P/F Ratio method is using which uses the child ever born and current age specific fertility rates (based on information on children born last year to currently married women). The result is based on the P2/F2 adjustment factors because in the country like India where fertility transition has already started in mid 1960s, fertility was undergoing rapid change. Under this situation, the fertility decline occurs mainly because of the women of older age who start controlling their fertility. P/F ratio method in this situation must be taken which is stable and consistent. Since the P2/F2 ratio is least affected by the declining fertility, it has been used here as an adjustment factor. Although P/F ratio method provides little higher estimate of Total Fertility Rate but they are more reliable than any other method. (Note: This method used by MORTPAK4.)

Ram and Chander Shekhar regression method: After reviewing the existing literature Ram et al. (2004) used the percentage of birth order $3+$ as independent variable and estimates of total fertility rate as dependent variable 1981 as well as 1991 census and developed a set of regression equations symbolic shown as:

\section{Exponential TFR $=12.2675 *$ EXP $(-0.0221 *(\mathrm{PFSB}))$}

Where, PFSB denoted the proportion of first and second birth order. The districts level estimates of fertility using birth order statistics with reference period 2001 from District Level Household Survey-Reproductive and Child Health are given in table 3. The level and differentials across districts of estimated total fertility rate are fairly consistent with the estimates of SRS. Therefore the method used in this study can be suggested as a potential tool to provide fertility rates at smaller administrative unit.

Gompertz Model for Trend analysis: This model used for trends analysis of total fertility rate during 1981 to 2007.Under this model, total fertility rate (TFR) is first rescaled to vary between 0 and 1 by applying the Following transformation:

$$
y=T F R-\alpha / s \quad(0<y<1) .
$$

Where $\alpha$ is the lower limit for TFR, and $s$ is the difference between the lower and upper asymptotes of

TFR.

In our case $\alpha=1.8$ (lowest TFR) and $\mathrm{s}=4.2$ (assumed Upper - Lower TFR) as per the SRS, 1981-2007;

Bihar

The transformed variable $y$ is assumed to fall with time $(t)$ according to the Gompertz curve:

$$
\begin{gathered}
\mathrm{Y}=-\ln [-\ln (T F R-\alpha / \mathrm{s})] \\
{ }^{\text {Product }} \text { ty }=-\ln [-\ln (T F R-\alpha / \mathrm{s})]^{* \mathrm{t}}
\end{gathered}
$$

Where $t$ is the time period between the base years and current year; for example in our case base years 1981 and current years is 2007 the time difference between these two time periods is 26 years. The Gompertz curve has been plotted against the product of $\left(\mathbf{t}^{*} \mathbf{y}\right)$, where $y$ is the annual change in TFR and $t$ is the time gap between the base year and current years.

\section{Gompertz Model for Projection:}

TFR are projected by single -year time interval using the Gompertz model

$$
\begin{aligned}
& \operatorname{TFR}=\alpha+\sigma a^{b t} \\
& \text { Or alternatively, } \\
& \quad L_{n}\left[-\left(L_{n}(T F R-a) /(\sigma)\right)\right]=L_{n}\left(-L_{n} \cdot a\right)+L_{n} \cdot b t \\
& \text { Where, }
\end{aligned}
$$




$$
a=\frac{T F R-\alpha}{\sigma}
$$

And

$$
\sigma=\mathrm{U}-\mathrm{L}
$$

Where $\mathrm{U}$ and $\mathrm{L}$ are the upper and lower limits of TFR respectively and $\alpha$ and $\mathrm{b}$ are constants.

The lowest threshold of TFR has assumed under United Nations projections (United Nations, 2001 to be ( $\mathrm{L}=\alpha$ $=1.8$ ) for this state and upper asymptote $(\mathrm{U})$ has been 7 for according National Commission on Population of India.

\section{RESULTS}

\section{Trends and changes in Total Fertility Rate in India and Bihar}

Table 1 presents the trends in Total Fertility Rate (TFR) during 1981 to 2007 in India and Bihar. It can clearly see from the table that there is variation among the increase and decrease in TFR in Bihar and India during different time periods. As the table presents that in 1984, there was an increase in TFR (5.9) than the past three years (in 1981, 1982 and 1983). Then again in 1992 and 1999, the TFR is slightly increased (4.6 and 4.5). Likewise in India, the TFR was increased (5.5) in 1986 and (5.3) in 1989.In 1990, there was a drastic decrease in TFR of India (4.6) in rural Bihar, there was a decrease in TFR accept in 1984(6).In rural India, we can see the instability for total fertility rate. The total fertility rate was highest in 1986 (5.7).The TFR was also high in 1989 and 1990 (5.4 for both the years). In 1984 (4.9) and 1993 (3.7), there was a slight increase in TFR for urban Bihar. In urban India, the TFR was highly increased in 1986 (4.9). It then came down to 3.2 in 1987.Then it again raised in 1989 (4.8) from 3.1 in 1988. There was little increase in TFR in 1992 but after 1992, there was a decrease in TFR up to 2007 (2). Similar result found (Pathak K. B. \& Murthy P. K.; 1987) in their study of India.

Figure: 1 Decadal percentage decline in Total Fertility Rate in Indi and Bihar according to place of residence, $1987-2007$

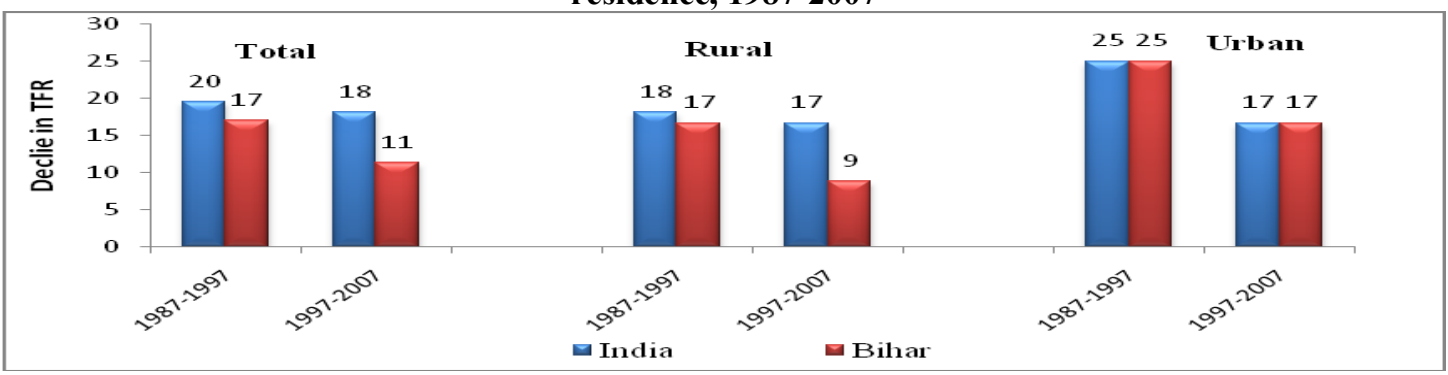

Figure 1 shows the decadal percentage change in TFR by place of residence for India and Bihar. The decadal percentage change in TFR is clearly evident that the change is more in case of India than Bihar. The decrease in TFR from 1987-97 was 20 percent in India and 18 percent in Bihar. The similar situation observed in the case of rural and urban areas, and however, the difference between India and Bihar in case of decadal change in TFR was more in rural than urban areas. A noticeable fact is that the change in TFR from 1997-2007 was more or less same in urban India and urban Bihar. It could be because of low urbanization, and Bihar is experiencing high fertility.

Figure: 2 Relationship between change in Total Fertility Rate to the level of TFR as indicated inGompertz model (based on Sample Registration System), 1981-2007

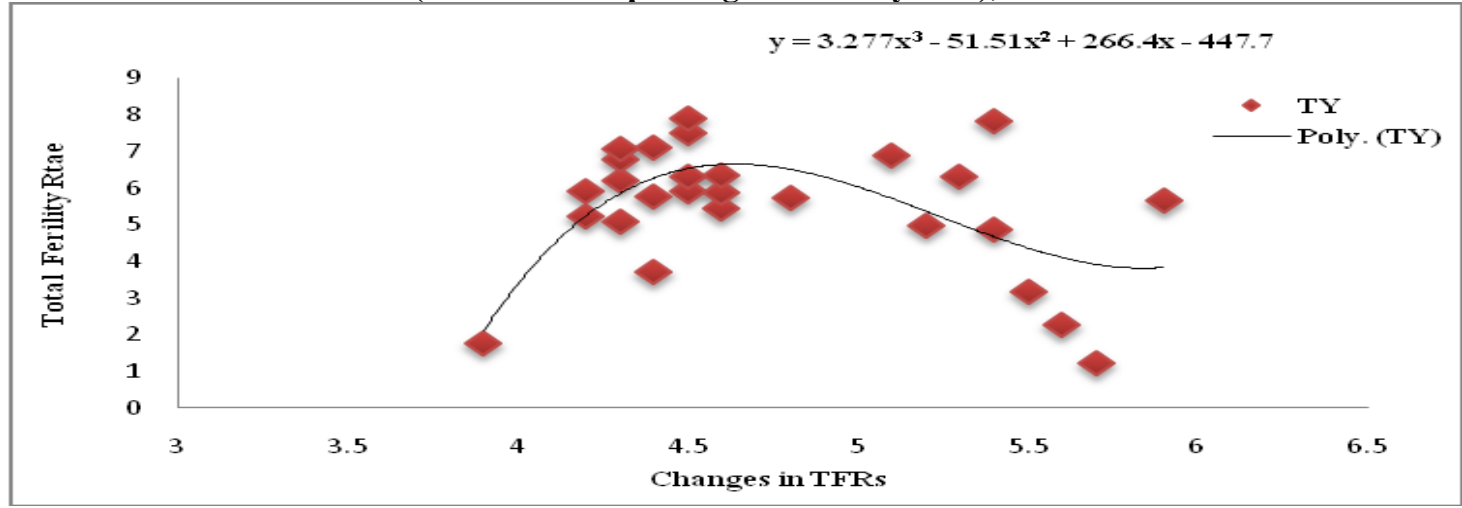


Figure 2 shows the rate of changes in TFR during 1981-2007. The basic question lies in the mind of the researcher is that when the most of the states were experiencing the rapid fertility decline, why the state of Bihar shows stagnation in fertility decline in the recent period? The reason could be that the period 1997 is a landmark in the history of family welfare programme in India. In this year, we adopted the Target Free approach for family planning programme and $\mathrm{RCH}$ programme also integrated with family welfare programme (Bhat, $\mathrm{P}$. N. Mari; 1994). Figure 2 shows the rate of changes in TFR during 1981-2007. The basic question lies in the mind of the researcher is that when the most of the states were experiencing the rapid fertility decline, why the state of Bihar shows stagnation in fertility decline in the recent period? The reason could be that the period 1997 is a landmark in the history of family welfare programme in India. In this year, we adopted the Target Free approach for family planning programme and RCH programme also integrated with family welfare programme. Figures 2 shows the Gompertz curve, plotted for Product of change in TFR and time on the level of TFR shows a curvilinear relationship. The fitted curve is base on $1.8(\alpha)$ and $5(\mathrm{~S})$ as lower and upper limits of TFR respectively, with the point of inflection at 4.7. The Gompertz curve is evident with the product change of TFR around 6 to 7 the fertility decline was more in pre-1997, which was stagnant with stagnation in product of changes around 5 in post-1997 and drastically dropped to 1.8 in 2007.

\section{Trends in Total Fertility Rate in districts of Bihar}

Table 2 shows trends of Total Fertility Rate (TFR) in the districts of Bihar during 1981-2001. Estimates are based on census. TFR in the state has slightly declined in last 20 years. For instance, it has declined from 5.2 in 1981 to 4.4 in 2001. Almost similar results observed across the districts. For all most all districts TFR was observed below 5 in 2001 except Katihar, where it is 5 during 2001. Even the TFR is still high among the districts, but some of the districts have performed comparatively better than others, these districts are-Patna, Aurangabad, Madhubani, Jehanabad and Muzaffarpur, where observed TFR are about 4.2 or below. In some districts, TFR are still high (about 4.7) and even declined very slowly in last 20 years, these districts areKhagaria, Kishanganj, Samastipur, Siwan and Gopalganj.

\section{Differentials in Total Fertility Rate in Bihar}

Differentials in TFR with selected background characteristics are examined using DLHS data, and results show in table 3. Result shows that TFR has declined by most of the background characteristics like place of residence, Hindu, Schedule Tribe, Other Backward Classes, etc. in during DLHS-2 to DLHS-3. The Muslims show high TFR of 5.3 than the Hindu, who has TFR of 4.3. Mistry M (1995) also found the similar result. But the temporally the TFR remains static among them. The TFR has declined higher $(0.3)$ in the urban area than the rural area $(0.1)$.

Table 4 shows trends in TFR among illiterate as well as literate from 1996-2007. It observed that TFR among illiterate has stagnated over the period. Moreover, it has increased from 4.9 in 1996 to 5.1 in 2006, but suddenly declined up to 4.7 in 2007. On the other hand, among literate TFR has declined continuously across the educational groups over the period. However, it is stagnated among those have no formal education.TFR has Maximum declined among who educated between class 10th and class 12th. It also observed that TFR has declined with the increased educational level, and similar results are observed cutting across the periods.

\section{Differentials in Contraceptive Prevalence Rate in Bihar}

To reduce fertility to desired level, increase influence contraceptive use among the population is very crucial and that why not only Government of India but also the Government of all over the developing world formulated Ante- natalistic population policies mainly focus to increase the popularity of contraceptive. Table 5 presents the result of contraceptive use among currently married women by different socio-economic groups in the state of Bihar from two different surveys i.e. National Family Health Surveys and District Level Household Survey. From the NFHS, it is observed that although the contraceptive use has increased from 23 percent to 34 percent in last 13 years but it also reflects that hardly one-third of women in the state are using any contraceptive. It observed that the contraceptive use has increased across the socio-economic groups over the periods but within the groups, differentials remained substantive over the periods.

Rural-urban differences are clear. For instance, the contraceptive use is only 31 percent in rural areas compared to 50 percent in urban areas during 2005-06. Moreover, similar differences are observed over the period. Educational status has positively associated with contraceptive use, for example among the illiterate women contraceptive use is only 20 percent compared to 53 percent among highly educated during 2005-06. Differences among socio-cultural groups are also evident from the table, from example contraceptive use are highest among the Hindu (37\%) than Muslim (19) in 2005-06. Similarly, it was higher among OBC caste compared to SC and ST. Wealth index also has a positive impact on contraceptive use, as it has increased from 25 percent among low-wealth indices to 54 percent among high Wealth indices. The similar differentials among 
caste, religion and wealth index are observed across the periods. (Ramesh, B.M., S. C. Gulati and Robert D. Retherford; 1996) Comparable result found that their study of India and state.

Results of DLHS also reflect the similar picture in Bihar. For example contraceptive use in the state has increased from 25 percent in DLHS-1 to 33 percent in DLHS-3, again indicating that only one-third of women are using any family planning methods in the states in 2007-08. Contraceptive use among different socioeconomic groups have shown increasing trends over the periods, but differentials in contraceptive use within the groups remained same over the periods and the results are similar as the findings of National Family Health Surveys.

Figure: 3 Trends in couple protection rate in Bihar, 1980-2005

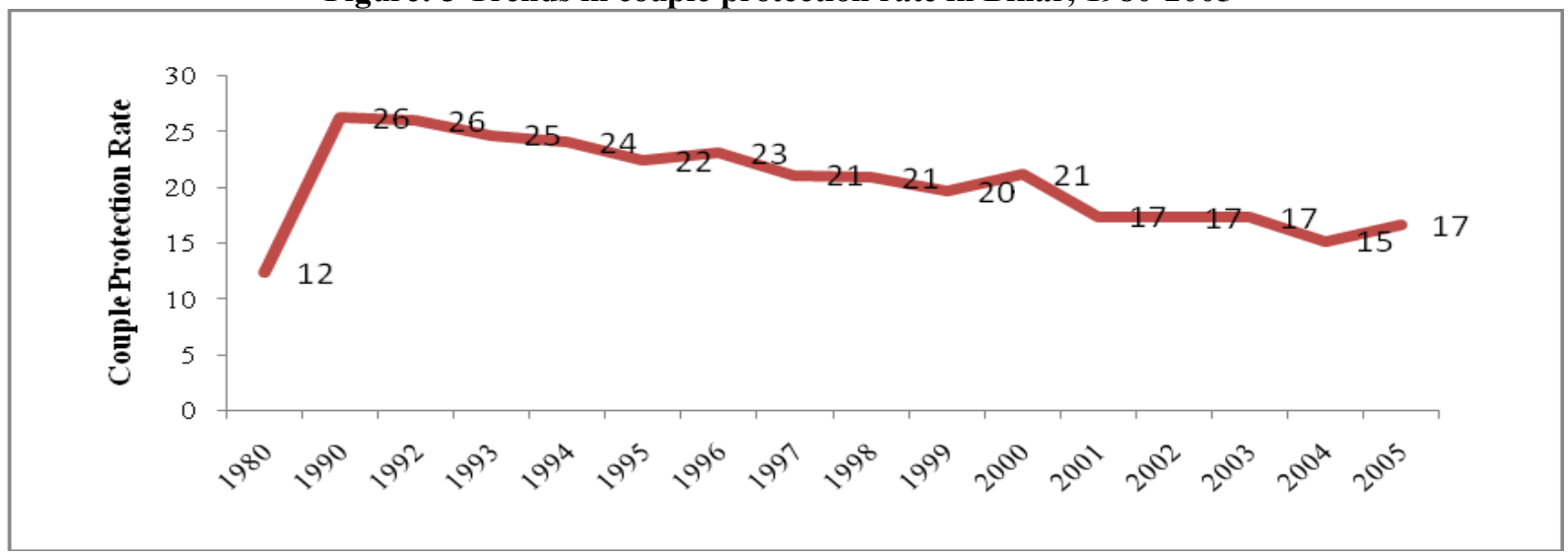

Source: Family welfare statistics, 2006 (Ministry Family welfare and Health, Government of India)

Figure 3 shows the couple protection rate (CPR) in the state of Bihar in last 25 years. As it observed, the CPR has increased very slowly in the states in last 25 years with very fluctuating trends. For instance, CPR has increased from 12 to 26 between 1980 and 1990, but again it has started continuous decline and between 1990 to 2000, CPR has declined from 26 to 21; again it has continuously decreased up to 16 percent in 2005.

\section{Projection of Total Fertility Rate}

Our National Population Policy-2000 has set the target to achieve the below replacement level of fertility by 2010 in the country and across the states. Recent estimates indicate that some of the states have achieved the goal of below replacement level of fertility. However, looking at the present estimates (NFHS-3 and SRS-2007) it seems difficult for Bihar.

Figure: 4 Projected Total Fertility Rate for Bihar, 1981-2060

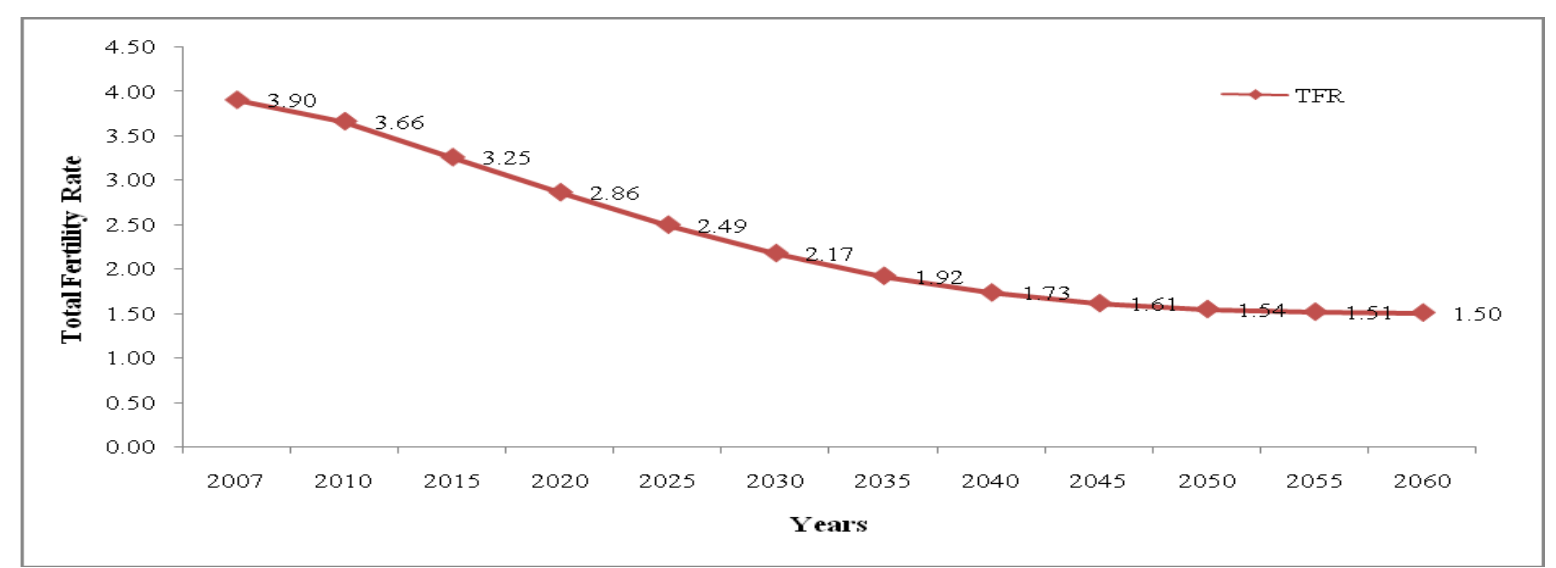

In that context, an attempt has been made to understand the prospects of fertility in Bihar in coming future and thus the projection of TFR for the state will for coming 50 years and result shows in figure 4 Result indicates that at present, projected TFR for the state is 3.66 (2010), which is far away from the below replacement of fertility. Moreover, the pace of fertility decline seems very slow in coming years. For instance, in 2020 it will reach the level 2.8 and by 2030, it will be reduced only up to 2.2. After very long (2035) time, TFR of the state will reach replacement level. 


\section{SUMMARY AND CONCLUSION}

This paper examines the trends, differentials and changes in fertility of Bihar. However, at initial stage fertility trends in India is also examined. Different data sets such as-Sample Registration System, Census of India, Districts Level Households Survey (DLHS), National Family Health Survey (NFHS) and Family Welfare Statistics (FWS) have used for different purposes. For example -Sample Registration System (1981-2007), Census of India (1981-2001), DLHS (1998-08) are used to examine the fertility trends. Trends and differentials in contraceptive prevalence rate are examined by using DLHS (1998-08) and NFHS (1992-06) data, while trends in Couple Protection Rate are examined by using FWS (1980-2005) data. Different approaches namely$\mathrm{P} / \mathrm{F}$ ratio, Ram and Chander Shekhar Regression method are applied to estimate the fertility rate while the trend in fertility is examined by using Gompertz Model. Determinants of fertility are examined by using the correlation matrix.

It found that pace of fertility decline is higher in India than Bihar during 1981-2007 indicating that Country will achieve the replacement level of fertility earlier than Bihar. The decadal decline in fertility in country and Bihar indicate the same picture. Percentage decadal decline in fertility is much higher in the country than Bihar in total as well as in the rural area. Interestingly in the urban area similar changes are observed in the country and the state. The Gompertz curve indicates that with the product change of TFR around 6 to 7 the fertility decline was more in pre-1997, which was stagnant with stagnation in product of change around 5 in post-1997 and drastically dropped to 1.8 in 2007 . Results from districts level trends analysis indicate that the reduction in fertility across the districts is as similar as states during 1981-2001. For all most all districts TFR was observed below 5 in 2001 except Katihar, where it is 5 during 2001. In some districts TFR are still high (about 4.7) and even declined very slowly in last 30 years.

Trends and differentials in fertility examined using DLHS data shows that it has declined maximum in the urban area, Hindu, Schedule Tribe and Other Backward Casts and among high wealth indices during DLHS2 to DLHS-3. In the case of religion, TFR is highest among Muslims (5.3), and Hindu (4.3) and patterns stagnant over the periods. In the case of wealth indices TFR is 5.0 among those who belong to low-wealth indices, while it is only 2.8 among high wealth index groups in 2005-08. According Sample Registration System (1996-2007) trends in TFR among illiterate and literate indicates that it has stagnated among illiterate over the period while substantive decline is observed among literate over the period as well as across the groups. Trends in contraceptive use among currently married women by different socio-economic groups in the state of Bihar indicate that the contraceptive use has increased from 23 percent from 1992-93 to 34 percent in 2005-06. It reveals that the contraceptive use has increased across the socio-economic groups over the periods with substantive differentials within the groups. Contraceptive use is higher in the urban area than rural. It is higher in Hindu (37\%) than Muslim (19\%), illiterate (20\%) than highly educated (53\%) during 2005-06. The similar differentials among place of residence, caste, religion and wealth index have observed across the periods. The similar results have observed from DLHS data. The couple protection rate (CPR) has increased from 12 to 26 between 1980 and 1990, but again it has started continuous decline during 1990 to 2000 (26 to 21 respectively); again it has continuously decreased up to 16 percent in 2005.

An important conclusion comes out of this paper is the fertility decline in Bihar is stagnant after 1997. The rate of decline is also decelerating since 1997. Moreover, an attempt has been made to understand the prospects of fertility in Bihar in coming future and thus the projection of TFR for the state has will do for coming 50 years. Result indicates that at present projected TFR for the state is 3.6 (2010), which is far away from the below replacement of fertility. It raises doubts about success of target free approach adapted into family planning programme. Moreover low literacy, low urbanization preceding poverty are the other important factors, which may be the cause for stagnant TFR in Bihar. There is needed to look at all those programs associated with population stabilization effort in the state. However, the bottom-up planning need for fertility reduction and population stabilization can success only. When the bottom - the grass roots level family welfare services providers - develops the capacity for assessing the family welfare and health services needs in an objective manner and using the knowledge so gained in providing quality family welfare services in an efficient manner.

[1]. Arriaga, E.E. (1983) Estimating fertility from data on children everborn by age of mother. International Research Document, No. 11 , US Bureau of the Census, Washington DC.

[2]. Bhat, P. N. Mari (1994). Level and Trends in Indian Fertility: a reassessment'. Economic and Political Weekly, December17-24: 3273-3280.

[3]. International Institute of Population Science and Macro International (2007), District Level Household Survey (Reproductive and Child Health), 2002-04: India: Mumbai: IIPS.

[4]. International Institute of Population Science and Macro International (2007), National Family Health Survey (MCH and Family Planning), 1998-99: India: , Mumbai: IIPS. 
[5]. International Institute of Population Science and Macro International (2007), National Family Health Survey (NFHS-2), 2005-06: India: Volume I, Mumbai: IIPS

[6]. International Institute of Population Science and Macro International (2007), National Family Health Survey (NFHS-3), 2007-08: India: Mumbai: IIPS.

[7]. Murthy M, Guio Anne Catherine and Dreze J. (1996). Mortality, Fertility and Gender Bias in India: A District-Level Analysis, Population and Development Review, Vol. 21, No. 4, pp. 745 - 782.

[8]. Mistry M (1995) Role of religion in fertility and family planning among Muslims in India. Indian Journal of Secularism , 3(2):1-33

[9]. Pathak K. B. and Murthy P. K. (1987) Rural-urban fertility differentials in India. Janasamkhya. Jun;5(1):41-59.

[10]. Ram F., Chander shekhar and Mohanty S.K. (2005). Human Development: Strengthening District Level Vital Statistics in India, by UNDP, International Institute for Population Sciences, Mumbai.

[11]. Ramesh, B.M., S. C. Gulati and Robert D. Retherford (1996). 'Contraceptive Use in India, 1992-93'.National Family Health Survey Subject Reports No.2. Mumbai: International Institute for Population Sciences

[12]. Registrar General of India. (2009), Compendium of India's Fertility and Mortality Indicators 1971-2009 Based on The Sample Registration System (SRS), India, New Delhi.

Table: 1 Trends of Total Fertility Rate in India and Bihar, 1981 to 2007

\begin{tabular}{|c|c|c|c|c|c|c|}
\hline \multirow[b]{2}{*}{ Year } & \multicolumn{3}{|c|}{ India } & \multicolumn{3}{|c|}{ Bihar } \\
\hline & Total & Rural & Urban & Total & Rural & Urban \\
\hline 1981 & 5.2 & 5.4 & 4.1 & 5.7 & 5.8 & 4.8 \\
\hline 1982 & 4.5 & 4.9 & 3.4 & 5.6 & 5.7 & 4.7 \\
\hline 1983 & 4.5 & 4.9 & 3.4 & 5.5 & 5.6 & 4.5 \\
\hline 1984 & 4.5 & 4.8 & 3.5 & 5.9 & 6.0 & 4.9 \\
\hline 1985 & 4.3 & 4.6 & 3.3 & 5.4 & 5.6 & 4.4 \\
\hline 1986 & 5.5 & 5.7 & 4.9 & 5.2 & 5.3 & 4.2 \\
\hline 1987 & 4.1 & 4.4 & 3.2 & 5.3 & 5.4 & 4.2 \\
\hline 1988 & 4.0 & 4.3 & 3.1 & 5.4 & 5.5 & 4.3 \\
\hline 1989 & 5.3 & 5.4 & 4.8 & 5.1 & 5.2 & 3.9 \\
\hline 1990 & 4.6 & 5.4 & 4.6 & 4.8 & 4.9 & 3.4 \\
\hline 1991 & 3.6 & 3.9 & 2.7 & 4.4 & 4.5 & 3.5 \\
\hline 1992 & 3.6 & 3.9 & 2.6 & 4.6 & 4.8 & 3.4 \\
\hline 1993 & 3.5 & 3.8 & 2.8 & 4.6 & 4.7 & 3.7 \\
\hline 1994 & 3.5 & 3.8 & 2.7 & 4.6 & 4.8 & 3.5 \\
\hline 1995 & 3.5 & 3.9 & 2.6 & 4.5 & 4.7 & 3.3 \\
\hline 1996 & 3.4 & 3.7 & 2.4 & 4.5 & 4.6 & 3.2 \\
\hline 1997 & 3.3 & 3.6 & 2.4 & 4.4 & 4.5 & 3.1 \\
\hline 1998 & 3.2 & 3.5 & 2.4 & 4.3 & 4.5 & 3.1 \\
\hline 1999 & 3.2 & 3.5 & 2.3 & 4.5 & 4.7 & 3.4 \\
\hline 2000 & 3.2 & 3.5 & 2.3 & 4.5 & 4.7 & 3.4 \\
\hline 2001 & 3.1 & 3.4 & 2.3 & 4.4 & 4.6 & 3.1 \\
\hline 2002 & 3.0 & 3.3 & 2.2 & 4.3 & 4.5 & 3.1 \\
\hline 2003 & 3.0 & 3.2 & 2.2 & 4.2 & 4.4 & 3.1 \\
\hline 2004 & 2.9 & 3.3 & 2.1 & 4.3 & 4.4 & 3.2 \\
\hline 2005 & 2.9 & 3.2 & 2.1 & 4.3 & 4.4 & 3.2 \\
\hline 2006 & 2.8 & 3.1 & 2.0 & 4.2 & 4.3 & 3.0 \\
\hline 2007 & 2.7 & 3.0 & 2.0 & 3.9 & 4.1 & 2.9 \\
\hline
\end{tabular}

Source: Sample Registration System (Registrar general of India)

Table: 2 Trends in Total Fertility Rate (TFR) among districts of Bihar, 1981-2001.

\begin{tabular}{l|c|c|c}
\hline \hline Districts & $\mathbf{1 9 8 1}$ & $\mathbf{1 9 9 1}$ & $\mathbf{2 0 0 1 *}$ \\
\hline Patna & 5.4 & 5.2 & 4.0 \\
Madhubani & 4.8 & 4.8 & 4.1 \\
Jehanabad & 5.7 & 4.8 & 4.2 \\
Aurangabad & 5.6 & 5.2 & 4.2 \\
Saharsa & 5.8 & 4.5 & 4.2 \\
Purba Champaran & 4.9 & 4.6 & 4.2
\end{tabular}




\begin{tabular}{l|l|l|l} 
Muzaffarpur & 5.3 & 5.1 & 4.3 \\
Bhojpur & 5.1 & 4.9 & 4.3 \\
Pashchim Champaran & 5.2 & 5.3 & 4.3 \\
Bhagalpur & 5.5 & 4.7 & 4.3 \\
Rohtas & 5.3 & 5.3 & 4.3 \\
Sitamarhi & 5.0 & 5.0 & 4.3 \\
Madhepura & 5.8 & 4.7 & 4.4 \\
Darbhanga & 5.4 & 5.5 & 4.4 \\
Navada & 5.7 & 5.3 & 4.4 \\
Gaya & 5.7 & 5.4 & 4.4 \\
Nalanda & 5.4 & 5.1 & 4.4 \\
Vaishali & 5.3 & 5.0 & 4.4 \\
Saran & 5.1 & 5.1 & 4.5 \\
Araria & 5.5 & 5.3 & 4.5 \\
Munger & 5.7 & 6.2 & 4.5 \\
Siwan & 5.2 & 5.4 & 4.6 \\
Gopalganj & 5.3 & 5.5 & 4.6 \\
Purnia & 5.5 & 5.4 & 4.6 \\
Samastipur & 5.4 & 4.8 & 4.7 \\
Begusarai & 5.6 & 5.4 & 4.7 \\
Khagaria & 5.7 & 5.5 & 4.8 \\
Kishanganj & 5.5 & 5.6 & 4.9 \\
Katihar & 5.7 & 5.5 & 5.0 \\
Bihar & 5.2 & $\mathbf{5 . 3}$ & $\mathbf{4 . 4}$
\end{tabular}

Source: Registrar General of India (1997) 'District level Estimates of Fertility and Mortality for and their Inter-relations with other variables, occasional paper No 1 of 1997.

Note: * Total Fertility Rate Estimated by Arriaga's P/F Ratio Method using census 2001.

Table: 3 Differentials in Total Fertility Rate in Bihar by selected socio-economic characteristics, 2004-08

\begin{tabular}{|c|c|c|}
\hline Background characteristics & 2002-04 & 2007-08 \\
\hline \multicolumn{3}{|l|}{ Residence } \\
\hline Rural & 4.6 & 4.5 \\
\hline Urban & 4.0 & 3.7 \\
\hline \multicolumn{3}{|l|}{ Education } \\
\hline Non literate & 5.3 & 5.2 \\
\hline 0-9 Year & 3.5 & 3.7 \\
\hline 10 above & 2.7 & 2.5 \\
\hline \multicolumn{3}{|l|}{ Religion } \\
\hline Hindu & 4.3 & 4.3 \\
\hline Muslim & 5.3 & 5.3 \\
\hline \multicolumn{3}{|l|}{ Caste } \\
\hline $\mathrm{SC}$ & 5.0 & 4.9 \\
\hline ST & 4.9 & 4.4 \\
\hline OBC & 4.5 & 4.4 \\
\hline Other & 3.8 & 3.9 \\
\hline \multicolumn{3}{|l|}{ Wealth index } \\
\hline Low & 5.0 & 5.0 \\
\hline Medium & 4.0 & 3.8 \\
\hline High & 2.8 & 2.8 \\
\hline
\end{tabular}

Total Fertility rate estimated by Ram \& Chander Shekar method TFR $=12.2675^{*}$ EXP $\left(-0.0221^{*}(\mathrm{PFSB})\right)$ 
Analyzing Fertility Trends and Future Prospect through Gompertz Model in Bihar State of India

Table: 4 Trends of Total Fertility Rate across the educational groups in Bihar, 1996-2007

\begin{tabular}{l|c|c|c|c|c|c}
\hline \multirow{2}{*}{ Years } & \multirow{2}{*}{ Illiterate } & \multicolumn{5}{c}{ Literate } \\
\cline { 3 - 7 } & & $\begin{array}{c}\text { Without Formal } \\
\text { Education }\end{array}$ & Below Class X & Class X - XII & $\begin{array}{c}\text { Graduate \& } \\
\text { above }\end{array}$ & Total \\
\hline 1996 & 4.9 & 3.8 & 3.5 & 2.8 & 2.1 & 3.2 \\
1997 & 4.8 & 3.8 & 3.5 & 2.8 & 2.0 & 3.2 \\
1998 & 4.9 & 4.3 & 4.0 & 3.1 & 2.3 & 3.0 \\
1999 & 5.2 & 4.3 & 3.3 & 2.4 & 2.1 & 3.2 \\
2000 & 5.2 & 4.6 & 3.3 & 2.6 & 2.1 & 3.3 \\
2001 & 5.0 & 4.6 & 3.3 & 2.7 & 2.1 & 3.3 \\
2002 & 5.0 & 4.0 & 3.1 & 2.3 & 2.6 & 3.1 \\
2003 & 5.0 & 4.2 & 3.5 & 2.3 & 2.8 & 3.0 \\
2004 & 4.9 & 4.2 & 3.3 & 2.5 & 1.8 & 3.2 \\
2005 & 5.0 & 4.3 & 3.2 & 2.4 & 2.3 & 3.2 \\
2006 & 5.1 & 3.6 & 3.0 & 2.0 & 2.0 & 2.8 \\
2007 & 4.7 & 3.7 & & 2.1 & 1.5 & 2.8 \\
\hline \hline
\end{tabular}

Source: Sample Registration System (Registrar General of India)

Table: 5 Differentials in contraceptive prevalence rate in selected socio-economic characteristics in Bihar (estimates from DLHS 1998-2008 and NFHS 1992-06)

\begin{tabular}{|c|c|c|c|c|c|c|}
\hline \multirow[b]{2}{*}{ Background characteristics } & \multicolumn{3}{|c|}{ DLHSs } & \multicolumn{3}{|c|}{ NFHSs } \\
\hline & 1998-99 & 2002-04 & 2007-08 & $1992-93$ & 1998-99 & 2005-06 \\
\hline \multicolumn{7}{|l|}{ Place of residence } \\
\hline Rural & 20.7 & 25.9 & 31.9 & 19.8 & 22.9 & 31.4 \\
\hline Urban & 37.7 & 44.7 & 47.5 & 42.5 & 38.9 & 50.6 \\
\hline \multicolumn{7}{|l|}{ Educational status } \\
\hline Illiterate & 18.5 & 24.2 & 29.1 & 17.6 & 20.5 & 29.0 \\
\hline 0-9 Year & 33.1 & 35.9 & 37.2 & 40.7 & 36.2 & 40.4 \\
\hline 10Year\&above & 36.0 & 52.2 & 48.8 & 45.7 & 40.3 & 53.1 \\
\hline \multicolumn{7}{|l|}{ Religion } \\
\hline Hindu & 25.1 & 33.3 & 36.1 & 26.0 & 27.3 & 36.9 \\
\hline Muslim & 7.9 & 15.8 & 14.8 & 7.5 & 9.1 & 19.0 \\
\hline \multicolumn{7}{|l|}{ Caste } \\
\hline $\mathrm{SC}$ & 17.2 & 20.6 & 25.5 & 14.5 & 19.5 & 23.2 \\
\hline ST & 14.2 & 23.1 & 24.1 & 16.4 & 14.1 & NA \\
\hline $\mathrm{OBC}$ & 22.0 & 30.5 & 34.1 & 24.7 & 34.3 & 38.3 \\
\hline Other & 30.7 & 42.0 & 40.3 & NA & 24.6 & 35.9 \\
\hline \multicolumn{7}{|l|}{ Standard of living index } \\
\hline Low & NA & 22.7 & 27.3 & NA & 16.5 & 24.9 \\
\hline Medium & NA & 38.9 & 37.7 & NA & 29.1 & 38.1 \\
\hline High & NA & 57.0 & 53.1 & NA & 48.8 & 54.2 \\
\hline Total & 25.0 & 31.0 & 33.0 & 23.1 & 23.5 & 34.1 \\
\hline
\end{tabular}

NA- Not Available 